\title{
Being with others during physical activity: experiences of wellbeing among adults with severe obesity
}

\author{
$\underline{\text { ABSTRACT }}$ \\ Background: The experience of physical activity is influenced by social relations \\ and gendered roles. Group-based lifestyle interventions are considered effective \\ in promoting physical activity, yet the experiences of being active with others are \\ unknown among individuals with severe obesity. \\ Purpose: To explore how individuals with severe obesity experience being with others \\ during physical activity. \\ Methods: A qualitative hermeneutic phenomenological study of repeated single gender \\ focus group interviews was conducted with adults living with severe obesity during \\ group-based lifestyle intervention. The Danish Data Protection Agency (J. no.1-16-02- \\ 425-15) approved the study. \\ Results: Three themes were developed: 'Enjoying safety, kinship and belonging \\ among peers'; 'Feeling like a failure is shameful: a sense of aversion' and 'Striving to \\ feel at home in physical activity: needing distance from others'. The themes were \\ merged into 'Achieving wellbeing may always be a challenge: not feeling at home in the \\ group or in body'. \\ Conclusion: Intersubjective and spatial dimensions of experiences are central and \\ influence how individuals with severe obesity can feel wellbeing and 'at home' in \\ physical activity. Physiotherapists should be aware of the individuals' vulnerability \\ regarding feelings of failure, aversion and shame as well as awareness of gendered \\ norms and roles.
}

Keywords: physical activity; obesity; lifeworld; gender; qualitative 


\section{$\underline{\text { INTRODUCTION }}$}

Severe obesity is associated with an increased prevalence of inactivity (WHO, 2014) and numerous and complex barriers to physical activity (Toft and Uhrenfeldt, 2015). In Denmark lifestyle changes are founded in the bio-medical paradigm addressing behavior in relation to the so-called KRAM-factors: Kost [diet], Rygning [smoking], Alkohol [alcohol] and Motion [exercise] to improve their health or prevent unhealthy lifestyles (Folkesundhed 2006). The success of lifestyle intervention targeted towards people with severe obesity is often related to weight loss or physical outcomes and directed at the extent to which a person's activity level corresponds with agreed recommendations (WHO, 2003). It has been proposed that lifestyle interventions for individuals with severe obesity should focus less on weight loss as the primary outcome and pay more attention to the independent benefits of being physically active (Aadland and Robertson, 2012; Baillot et al, 2015) and to a greater extent attend to existential experiences (Mik-Meyer, 2014).

The terms physical activity and exercise are often used interchangeably, when in fact they have different meanings. Physical activity is defined as any bodily movement produced by skeletal muscles that results in energy expenditure. Physical activity in daily life can be categorized into everyday tasks, mobility for transportation (walking and cycling) and climbing stairs. Exercise is a subcategory or a type of physical activity, which is planned, structured, and repetitive and aims towards improvement or maintenance of body weight, physical skills and health (Caspersen, Powell, and Christenson, 1985). The approach in this study is that participating in any physical activity is more beneficial than being physically inactive (Brach et al, 2004) and that the experiences of physical activity and exercise are influenced by social relations and gendered roles of women and men (Young, 2002). 
Physical activity interventions aim to increase physical activity level among the inactive individuals to obtain health benefits (Hills and Byrne, 2004), and/or weight maintenance in individuals with severe obesity (Donnelly et al, 2009). However, maintaining the activity level after intervention is found to be an on-going challenge (Tate et al, 2007). Being unable to remain active may make patients appear unsuccessful and physiotherapists (PT) may feel disappointed and unable to help and find it difficult to speak about and to understand the patient's lifeworld experiences (Groven and Heggen, 2018). This is why encountering obese patients individually or in group-based lifestyle intervention programs can be a challenge. Recent studies have enhanced the understanding of what it is like to live with obesity as an existential challenge (Haga, Furnes, Dysvik, and Ueland, 2019b; Ueland, Furnes, Dysvik, and Rørtveit, 2019) and how lifestyle change for weight loss in the long term presents existential aspects that are deeply personal (Natvik et al, 2018).

Wellbeing is a keyword in the The World Health Organization (WHO) definition of health, which "goes beyond healthy lifestyles to wellbeing" (WHO, 1986) and for example, a Danish WHO-5 Questionnaire has been developed to measure mental wellbeing (Psychiatric Center North Zealand, Psychiatric Research Unit, 2017). Empirical research has reported that individuals with severe obesity lack wellbeing in physical activity (Ekkekakis and Lind, 2006). However, qualitative insight into how individuals with severe obesity experience existential wellbeing in relation to physical activity is lacking even though a growing body of research on complex existential challenges in relation to body, life and existence exists (Haga et al, 2019b; Ueland et al, 2019; Haga et al., 2019a; Ueland, Dysvik, and Furnes, 2020). 
It has been suggested that HCP should aim for promotion of wellbeing and reduction of weight stigma in order to be supportive (Dikareva et al, 2016; Dahl et al, 2014; Rand et al, 2017) and it has been emphasized that social and environmental factors were important barriers to physical activity in individuals living with severe obesity (Baruth et al, 2014; Dahl et al, 2014; Denison et al, 2015; Groven and Engelsrud, 2010). The group setting for interventions has been found to add negative experiences of one's own identity as obese (Bombak, 2015). Additionally, physical activity may contribute to experiences of weight stigmatization (Hunger et al, 2015), especially among women (Monaghan and Malson, 2013), which may become a barrier to physical activity (Vartanian and Novak, 2011). On the other hand, physical activity with others may contribute to a feeling of connectedness that can prevent a sense of loneliness and isolation (Piana et al, 2013) and provide a positive relationships with other people, which are important to initiate and maintain physical activity participation (Thomas et al, 2008; Wiklund, Olsen, and Willen, 2011).

A systematic review and meta-synthesis of qualitative literature on facilitators and barriers to physical activity among individuals with severe obesity by Toft and Uhrenfeldt (2015) reported that existential suffering and wellbeing were related to a sense of "Belonging with others", or its absence, e.g. with HCPs, in private network and in group activities with peers (Toft and Uhrenfeldt, 2015). Likewise, a review found that a sense of belonging was provided in group-based weight management interventions for adults with severe obesity (Skea et al, 2019). However, in both systematic reviews, the male perspectives were underrepresented. 
In Denmark marginalised subgroups of men, e.g. severely obese men, are identified as a specific population when planning health initiatives (Danish National Board of Health, 2010). Gendered differences in everyday health care practice are guided and constrained by social norms and situations, i.e. gender is a part of a person's lived experience of being active in the world (Saltonstall, 1993). Further gender is not necessarily binary and is closely linked to identity. Much literature has pointed to stereotypical 'masculine' and 'feminine' health behaviour (Hunt et al, 2007), where men are less engaged with health and wellbeing issues than women (White et al, 2011). Therefore, experiences relevant to gender are important to investigate in order to provide different aspects of a phenomenon (Bullington, 2006), e.g. wellbeing in physical activity. It is relevant in the clinical context of lifestyle intervention, where men are underrepresented among HCPs and patients and there is a risk of enacting stereotyped gendered norms by both groups, which may limit the possibilities of making lifestyle changes.

To the best of our knowledge, the experiences of physical activity among women and men with severe obesity during group activities and in everyday life are not yet reported. Also little attention has been paid to the lifeworld experiences of exercise with others, in group settings.

The purpose of our study is to explore how individuals with severe obesity experience being with others during physical activity. Specifically we asked: "How do women and men with severe obesity address, talk about and describe and refer to their experiences of being physically active with others, while undergoing lifestyle intervention?

\section{THEORETICAL FRAMEWORK}

The study is based on hermeneutic phenomenology founded in the existential German philosophy of Being-with-one-another in the world in a spatial manner and 
intersubjective dimensions of experience (Heidegger, 1962/2008). As human beings, we influence and are influenced by the world and other human beings and their norms (Gadamer, Misgeld, and Nicholson, 1992). Therefore, being active is always part of a shared lifeworld as acting, embodied and social human beings (Heidegger, 1962/2008). The study is guided by Heidegger's existential theory, in that, any experience of wellbeing is both a way of being-in-the-world, as well as a felt sense of what wellbeing is like as an experience (Galvin, 2013). Furthermore, in order to deepen the understanding of the participants' existential lifeworld experiences of being with others in physical exercise, we used dialogue to access experience, where different horizons are shared in language (Gadamer, 1975/2013). Todres and Galvin (2010), building on lifeworld theory, lay out a philosophical foundation for ideas about wellbeing as a sense of dwelling and a sense of mobility intertwined. They later (Galvin and Todres, 2011) describe a conceptual framework that delineates eighteen different kinds of wellbeing by unfolding a 'dwelling-mobility' lattice, which takes these theoretical ideas in practical directions. Here dwelling emphasizes a settling into the present moment/situation with acceptance of things as they are, whereas mobility describes all the ways that one can have access to the feeling of possibility. The deepest possibility of wellbeing is experienced when these two, dwelling and mobility, are integrated, and wellbeing experience is always in relation to their falling away, an absence of dwelling or an absence of mobility, giving rise to forms of suffering (Galvin and Todres, 2013). The conceptual framework is sensitised by six lifeworld domains, which are the experiences of lived time; lived space/spatiality; identity; lived relations/intersubjectivity; mood and the lived body/embodiment (Galvin and Todres, 2013). For the purpose of this paper the lifeworld domain of lived relations, i.e. intersubjectivity or "Being-with" others (Gadamer, 2013:127) and relationality or 
communality (Van Manen, 1997:101), is focused on. Within Todres and Galvin's framework, this refers to for example, how we are in the world with others which may manifest as mysterious interpersonal attraction, i.e. feeling attracted to the novelty of another and interest in other people by wanting to get to know them (mobility emphasis), and a sense of belonging, or even kinship, i.e. feeling comfortable and relaxed with others, feeling at home with others (dwelling emphasis) and in the deepest sense of wellbeing (dwelling and mobility with an intersubjective emphasis) achieving a sense of mutual complementarity with others (Galvin and Todres, 2011). These conceptual ideas were used as a sensitising background in exploring how individuals with severe obesity experience being with others during physical activity.

\section{METHODS}

The present paper is part of a larger study aiming to gain in-depth understanding of the temporal experiences of well-being in the context of lifestyle changes in both a clinical setting and in the participants' home setting among women and men with severe obesity. The same participants were individually interviewed prior to intervention and at the end of the intervention (at 6 months) (Toft et al, 2020) and at 18 months, i.e. one year after the end of intervention (Toft, Nielsen, Uhrenfeldt, 2020). All interviews conducted by first author.

The participants were purposefully recruited by a secretary of the department of lifestyle rehabilitation from a waiting list of patients awaiting lifestyle intervention by the criteria: adult $\geq 18$ years, $\mathrm{BMI} \geq 40 \mathrm{~kg} / \mathrm{m}^{2}$. She contacted the patients until eight women and eight men were recruited for repeated interviews including the focus group interviews (FGIs) of this study. 
The participants participated in six months of group-based lifestyle intervention with three four-day in-hospital admissions at a Danish public hospital with held a physical activity component of different types of physical activity and exercise (See table 1).

(Insert table 1 here, please).

Four focus group interviews were undertaken, these were organised as single gender groups and conducted in two rounds. The first round was conducted at the start of the intervention and second round at the end (at 6 months). The groups were purposively organised as homogeneous with regard to BMI status and gender (Morgan, 1997).

The first author's experience as a PT working with individuals living with severe obesity provided pre-knowledge and pre-understanding of the topic in question (Brinkmann and Kvale, 2015). Her experience in asking questions and moderating group dynamics was considered an advantage. Interview guides were developed for each FGI (Krueger and Casey, 2009). The first FGI round used the opening question: "Could you please tell me about a significant experience of being physically active with others, and what the experience means to you?". The second FGI round was conducted to add depth to the data of the first FGI. The use of the 'Picture Sorting method' was chosen to increase the involvement in the discussions in a more reflective and enjoyable way (Colucci, 2007), assuming it could add breadth to the research findings gained from individual interviews. The method was piloted in group of individuals prior to use. The FGIs were conducted in a meeting room at the hospital in the spring and autumn 2016, and they all lasted as planned for 90 minutes. 
The study was approved by the Danish Data Protection Agency (J. no. 1-16-02-425-15). The study was performed in compliance with the Helsinki Declaration (World Medical Association, 2013). All participants were informed orally and in writing and gave written informed consent to participate. They were guaranteed anonymity and were informed of the right to withdraw from the study at any time without reprisal.

\section{$\underline{\text { Analysis }}$}

A phased analysis based on a hermeneutic approach was used in three steps of questioning: (1) "What do participants address?" (2) "How do they talk about it?" and (3) "What experiences do they refer to and describe?" (Fleming, Gaidys and Robb, 2003).

In the first step all FGIs were audio and video recorded and transcribed verbatim by a transcriptionist, and afterwards verified for accuracy by the first author. The audio recordings were listened and re-listened to and transcripts were read and re-read to cluster expressions that reflected the meaning of the text as a 'whole', i.e. searching for the topics addressed by the groups. In the second step, each participant's talk was interpreted by the first author, in order to understand their experiences through the medium of a language (Gadamer 2013). Via dialogue she used her own preunderstanding, sensitised by the well-being theoretical framework to identify common themes of each FGI and moved back and forth between the 'whole', and the 'parts', i.e. themes addressed and examples and descriptions given by each participant. In the third step, the understanding of the subject matter was expanded by relating the individual's experiences to the reflected meaning of the 'whole' text including experiences or contexts that were referred to.

The first round of FGIs was analysed before round two in relation to step 1 and 2. In step three the first and second round were merged and the data was interpreted and 
sensitized according to the conceptual framework. The interpretation was conducted in a reflective way with regular discussions of pre-understanding and understandings with co-authors in a circular process of moving between data on a group level and reflecting on the data from the individual's understanding (Smythe et al, 2007).

\section{$\underline{\text { RESULTS }}$}

Seven women (30-57 years) and eight men (25-68 years) were included for first FGI round. The participants were in the same intervention group, however some changed their dates for hospitalisation and were not present at the time of the second FGI and one woman dropped out of intervention. For that reason, additional three women and one man were recruited only for the second interview round to reach the ideal of four to seven participants in each group (Jones, Brown and Holloway, 2013).

The experience of what it is like to be with others (intersubjective dimensions of experience) during physical activitywas addressed through three themes: 'Enjoying safety, kinship and belonging among peers'; 'Feeling like a failure is shameful: a sense of aversion' and 'Striving to feel at home in physical activity: needing distance from others ' representing a continuum of experiences of wellbeing and suffering, i.e. the absence of wellbeing to varying degree. The existential experiences were connected as 'Achieving wellbeing may always be a challenge: not feeling at home in the group or in body'. (see table 2).

(Please insert table 2 here) 


\section{'Enjoying safety, kinship and belonging among peers'}

Wellbeing within the domain of intersubjectivity was related to being among peers, i.e. people living with obesity and wanting help to make lifestyle changes, was addressed by both women and men. Being among peers brought a kind of safety, kinship and belonging during physical activity intervention. The participants felt safe among other individuals with severe obesity and a kind of kinship due to their experiences of the same kind of weight stigma. Being among peers opened up a new willingness to participate in physical activity. They worried less about bodily appearance, which was felt as a liberating experience:

"Among like-minded people, there isn't anyone around to laugh at you if you fall over during some ballgame or if your stomach flops out a little". Male: 25 years old. It was a new kind of belonging, making room for being who you are and with a minimal risk of being embarrassed.

The women talked about the relief of being able to share personal issues and mirroring their own situation in others' with a mutual history of similar problems and experiences. It gave them a feeling of an implicit understanding and kinship. Peers were referred to as being women of large body size and with similar limitations, and being in a group of peers eased their acceptance of themselves in relation to being physically active. They also talked about how they felt no sense of belonging due to uncertainty and the risk of looking ridiculous, chubby, falling over or breaking funiture or equipment. Among peers they felt safe and courageous, which was needed to be able to participate in unfamiliar activities. A woman chose to try yoga for the first time and felt courageous in doing so. She described the experience:

I feel like a bull in a china shop. I feel really clumsy [doing yoga]. All those positions you have to get into...if I'm not able to do them, I get mad at myself 
and think "I'm too fat for this anyway" and "is everyone looking at me" standing there with my ass in the air, looking like a huge house. I didn't really enjoy that. Female: $>30$ years old.

Wellbeing was lacking during the activity and it seemed a struggle for her to accept her own imperfection. However, she was the only one who expressed that appearance mattered in the group of peers. Still, feeling courageous brought her wellbeing and brought a new desire to try other new activities. Those who developed less critical thoughts about themselves experienced an openness to participate in exercise with others in different settings. The women talked about how pleasure was experienced in social walks, shopping with friends, housework or playing with children. They distinguished between physical activity and exercise as they preferred everyday physical activity without the embodied experiences of sweating and heavy breathing. Especially, the company of others was bringing wellbeing and increased their desire to be active. The challenge for this woman was that she found herself incapable of doing exercise on her own:

"It's been a real struggle for me. I've taken the easy way out so many times because I actually really want someone to go with". Female: 55 years old. She experienced that enjoyment, comfort and community in that were absent in her everyday life.

The men tended to talk about wellbeing in physical activity in a different way. They emphasized their new abilities and performance in comparison with other men in playful games, tests and competitions. Performing well was associated with feelings of success and pride, and the men had such experiences among peers during intervention: "[We] had to walk for six minutes. So we had to walk as many meters as we could and I came in second place. That was a giant, giant, giant victory for me". Male: 53 years old. 
Like most other men in the group, this man experienced that by challenging himself he was able to perform well, which was opposed to his usual feeling of being a failure in exercise and sports. However, the desire to perform better was likely to make some of the men over-do physical activity and suffer the defeats of pain and fatigue on a longterm basis. Additionally, playing sports with others was found fun among the men, as they found it added cheerfulness and joy. This kind of wellbeing increased their desire to participate in more activities during intervention. This 45 year old man used to love playing handball, however back pain had made him stop trying, but during intervention he gave it a new try:

"I've been so incredibly proud of myself the last couple of nights where we've gone to play ball at the gym".

This experience contrasted his previous experiences of physical activity, which for years had not been related to experiences of enjoyment and pride, but rather a matter of exercise to lose weight and preserve physical health. However, none of the men became active with ball games in their home environment as they found themselves physically incapable of fitting into an ordinary local club, where they would feel no sense of belonging.

Physical activity in a group setting of peers was a new way of engaging and connecting with other people for most of both the women and men. The theme revealed that the intervention offered a temporal relief of loneliness and provided a feeling of wellbeing. Still, some participants preferred being on their own when doing physical activity and exercise, as it was found more safe and comfortable.

Friendly and competent PTs added to the feeling of wellbeing in terms of providing security, support and confidence to the participants and to the group during physical activity. However, when there was a threat to a sense of belonging, with little mutual 
interpersonal complementarity and even sometimes an expressed sense of aversion, wellbeing was lacking, and findings provided examples where there was limited interpersonal mobility. Such absences of wellbeing seemed to manifest as feelings of shame and a need to take distance from others.

\section{'Feeling like a failure is shameful: a sense of aversion'}

Lack of wellbeing or suffering within the domain of intersubjectivity was related to being with others during physical activity and experiencing a feeling of failure in physical activity. There was a kind of sense of exile, sense of exclusion or a need for avoiding others in certain contexts.

The women tended to address intersubjective suffering in terms of feeling blame and shame. They talked about how their limited activity level made them look like human failures, who were incapble of living in accordance with the health norms of the society. Some of them blamed themselves for being incapable of doing activities with their children, acting like good role models and being responsible mothers, which was the case for this mother aged 30, who did not join her daughter in the swimming pool due to her large body size, which she was ashamed of:

It makes me sad, that I cannot jump in [the water]...It makes me frustrated and angry at the same time, because as a mother you want to support your child. But right now you can't... and then you feel "I'm just fat and no good at anything". Only the women shared that they were responsible for younger children, which was a great concern to them.

Sex was considered a way of being physical active, but it was impossible to find pleasure in sexual activites with their partner when feeling unattractive, worthless and 
shameful of oneself: "You feel like you do it out of obligation because you're not happy with your own body. I struggle with that. Sometimes I'll say, just do it - so you can get it over with". Female: 41 years old.

The lack of wellbeing in sexual activities added to the feelings of being a failure as sexual partners, which reduced their sexual activity and compounded their feeling of being a human failure unable to take reponsibility. The women experienced suffering when being reminded of their previous sense of self and their lowered desires.

The men did not address sexual issues or their obligations or responsibilities at home in any of the discussions. They addressed lacking wellbeing when feeling like a failure in physical activity, in different ways e.g. when excluded in group activities due to pain, fear or incapability:

The greatest defeat I've experienced was the time I sat on a chair while everyone was jumping around on the [gymnastic] ball. They looked like they're having fun but I couldn't participate. I mean, I was terrified that the ball would burst - and how was I going to get up off the floor if the ball burst. Male: 53 years old.

He felt, that withdrawal from group activities and only being able to watch the others was shameful. Others chose to do activities on their own, when they felt the activities were not adapted to their physical capacity or they would make up excuses or lie to hide their bodily limitations. The men talked about how other people's normative attitudes made them feel obligated to be physically active to lose weight in order to act responsibly. They experienced exercise to be an exhausting task, especially when feeling pressurized to increase the amount or intensity. The men described how they suffered from shamefulness when exhausted in their exercise efforts, feeling limited 
freedom to participate and feeling pressurized into dishonesty in order not to avoid humiliation. For example, this man aged 60 was invited out with his colleagues:

I really wanted to go...but I had to kind of lie or lie...I actually told them , that I could not attend the paint ball battle and the sleep over...That's really annoying ...but I just knew I couldn't...

There was a tension between the wellbeing of being with others and preferring to be alone because of feeling aversion towards oneself and others. The aversion manifested itself as shame of being a failure and added a kind of suffering in the interpersonal realm, which had the potential to undermine physical activity participation during intervention.

'Striving to feel at home in physical activity: needing distance from others' The physical activity setting and the experiences within the setting, i.e. the domain of spatiality, were addressed as most important and closely related to their experiences within the domain of intersubjectivity. Places, environment and surroundings provided different experiences of feeling at home -or not in physical activity and exercise, and in combination with the people present, it influenced the extend to which the participants felt welcome, safe and relaxed. Striving for wellbeing made the participants seek nature, which was suited for both outdoor activities and rest, as they would be distanced from others and feeling at home. The men emphasized the wellbeing of going hunting or fishing alone. Suffering was experienced in places where the participants did not feel at home because they felt compared and judged by looks and performance by others:

I would never go to a public swimming pool. Only if I could go with someone who was big, because I would feel like a laughingstock. Everyone would look at me and talk about me and bad mouth me. Male: 42 years old. 
Meeting thin or fit people, especially strangers, would bring the feeling of being alienated as "abnormal". This is suffering of aversion runs through the fears that others will be averse to them and add a kind of self aversion, which is linked to feeling shameful. The women gave examples of how they would distance themselves from thin women and talked about "them and us". Moreover, in striving to feel at home the women described how they would distance themselves from exercise places, which were considered unsafe, e.g. in a dressing room, swimming pool or gyms.

There are so many people who have starred at you and you feel like, "I'm just fat and no good for anything", and then it starts up again. Your confidence is even lower and you kind of give up on everything - nothing matters anyway. Then I feel uncomfortable being there and just want to go home. Female: 41 years old. Getting undressed and showing one's body would make one feel particularly vulnerable to other people's comments and glances. The participants strived for the wellbeing of being accepted as they were, and strived to be viewed as "normal" in order to feel at home.

Being unable to feel at home in the physical activity setting was related to the risk of experiencing weight stigma, and staying at home was a way of eliminating the risk of being judged wrong, flawed and imperfect by others. The men gave examples of how they did not need the distance from others in the hospital setting during intervention. However, wellbeing in the hospital setting was challenged by group dynamics, e.g. lacking tolerance and normative attitudes between individuals. 
'Achieving wellbeing may always be a challenge: not feeling at home in the group or in body'.

The participants referred to numerous existential experiences related to different kinds of wellbeing, lack of wellbeing and suffering. Achieving wellbeing was challenged by the risk of weight stigma. In this way, other people and specific physical activity settings challenged their desire, courage and willingness to participate, e.g. where and with whom they wanted to be physically active. Moreover, achieving wellbeing during physical activity was challenged by their lacking acceptance of self, i.e. appearance, body size and capability and in some situations it brought a sense of suffering. The assessment of suitable groups of peers and support was challenged in their home environment. During the group intervention led by PTs at the hospital their wellbeing was challenged by non-adapted activities and by group dynamics. Nonetheless, more and new possibilities of wellbeing in physical activity were experienced by the participants during the time of lifestyle intervention, which made some participants engage in new types of activities in their home setting. To feel at home in physical activity is a kind of wellbeing, an existential dwelling, which means coming to terms with and being willing to be present in a certain place or situation despite vulnerability, suffering and pain. Dwelling seems to provide energy and mobility to become of stay physically active.

\section{DISCUSSION}

We chose to take an existential perspective of wellbeing to explore how individuals with severe obesity experience being with others during physical activity. Specifically, we aimed to answer: "How do women and men with severe obesity address, talk about and refer to their experiences of being physically active with others, while undergoing 
lifestyle intervention? The aim of the analysis is not to compare male and female perspectives in a summative way, but rather to notice the way in which each group talked about their experience as a way to access in-depth insights and to gather in-depth lifeworld experiences about being physically active with others.

Our findings reflect findings of other studies. Women with severe obesity have been found to feel more recognized, accepted and less shameful when exercising with peers (Groven and Engelsrud, 2010). We found that the participants experienced that being with peers provided a new kind of wellbeing in terms of having a mutual identity in the group. The connectedness they felt during intervention seemed to transform an isolated "I" into a unified "we", which additionally brought a kind of dwelling in their own individual identity and a contemporary mobility (Hitch, Pépin, and Stagnitti, 2014). This resonates with previous findings reporting how group interventions enabled a mutual connection between individuals with severe obesity and offered a collective lens for understanding and sharing of experiences (Tarrant et al, 2017).

In addition, we also found that the group member not necessarily experienced togetherness and understanding as intolerance and normative attitudes, seemed to exist and could block wellbeing and reduce physical activity participation. Conflicts between participant with severe obesity have been identified previously (Dahl et al, 2014) and preventing and tackling such conflicts is an important task for HCPs to ease the patients' participation (Tarrant et al, 2017).

We suggest that PTs specifically aim be attuned to each individual's sense of wellbeing in order to establish a safe and trustful setting and prioritize establishing ways to experience a sense of belonging. This could include being sensitive to how being with others offer kinship and belonging or how absences of a sense of kinship and belonging 
are manifest. Being attuned to these kinds of interpersonal manifestations of wellbeing in a range of situations can underpin strategies that can support respect and trust in the exercise groups, especially if the participants are strangers and of different body sizes.

Our findings emphasize that wellbeing established in group-based activities in a hospital setting may serve the purpose of providing an embodied way for individuals to meet 'the world' and gain new experiences in a safe way. Such new experiences may develop the awareness of the individual's own values, likes or dislikes (Gadamer, Misgeld, and Nicholson, 1992). In a hermeneutic sense, new experiences of wellbeing have the potential to make a radical shift in one's previous views (Holroyd, 2007), e.g. one's view of possibilities, interpersonal dwelling with a sense of kinship and belonging and feeling of at home when physically active.

We also suggest that PTs are attuned to the individual's sense of suffering. Shame is often attached to persons, who experience being imperfect or not fitting into the surroundings, e.g. people who are not living in accordance with the health norms and body ideals of the society. Viewing oneself as an obese person may be experienced as being different from others (Christiansen, Borge, and Fagermoen, 2012), which may bring feelings of being objectified and alienated as a human being (Ueland et al, 2019). Our findings reveal how feeling like a failure is shameful for the participants, and that feeling a failure in physical activity and exercise is related to the person's sense of being a human failure, and a more deeply a sense of aversion that requires distance from others. These finding related to physical activity are similar to earlier findings that obese individuals experience that their large bodies make them feel like failures (Haga et al, 2019a). In this way shame is existential, as it is linked to a person's identity, i.e. 
viewing the whole person as totally useless (Nussbaum, 2009) if they are inactive or obese. Being severely obese and inactive may entail the feeling of being revealed by the world as being fallible and being a moral failure, and easily judged to deviate from the standard norms of appearance and health (Puhl and Heuer, 2010). The discredit of a person due to being seen as obese is the core of weight stigma and may lead to considerable harm to the patient (Puhl and Heuer, 2009) and influence individuals' experiences of wellbeing (Lewis et al, 2011). Living with obesity is found closely connected to experiences of weight stigma, which is known to add to the individual's sense of shame (Ueland, 2019).

In this way our study presents new empirical data of different experiences of physical activity lack of wellbeing and suffering were experienced due to social and moral norms related to physical activity and exercise, which may also exist in the healthcare setting. However, the participants experienced being different, wrong and shameful to a greater extend in their everyday life, e.g. when going to a public swimming pool. The participants of our study would avoid persons and situations that potentially held the risk of humiliation or embarrassment, as it could activate their feelings of aversion. Interestingly, some women in our study seem to develop a kind of acceptance of their imperfection during intervention, and they become capable of facing their fear of failure in relation to enter public swimming pools. Some of our participants were able to establish the courage to participate in different exercise settings and experience a sense of pride of being capable, which can be considered to be the opposite of shame, and a way to counterbalance the two (Ueland, 2019). 
There seemed to be taboos related to shame, which were relieved in the participants of our study by sharing their feelings of failure with others. We argue that suffering from shame may be relieved by talking about how we understand and see each other, and how we can accept being humans with perceived weaknesses and deficiencies. Individuals with obesity may experience high levels of judgment for their weight and aversion towards them, especially in exercise spaces, which in particular are considered to be related to weight stigma for those with larger bodies. Previously, it has been found that women gave up on physical activity participation, because they felt ashamed and uncomfortable within the physical activity setting (Groven and Engelsrud, 2010), which is why judgement-free exercise settings are suggested to enhance wellbeing (Han et al, 2018). We found that the hospital setting and a group of peers enhanced wellbeing in a way that brought the individuals the courage to participate in activities, that individuals with obesity would typically avoid (Pickett and Cunningham, 2016; Pickett and Cunningham, 2017) due to discomfort of weight stigma (Puhl and Heuer, 2010).

Our themes suggest a tension between the wellbeing related to being with peers and the need of keeping distance from others, which influenced the beneficence of the group based intervention. Therefore, we agree that assessment of different exercise settings is needed to meet the individual's preferences (Wiklund, Olsen, and Willen, 2011) with voluntary and flexible possibilities to choose, e.g. to be outdoors, being alone or opportunity to join groups activities. The environment and physical surroundings may provide possibilities for mobility in wanted and valued ways, and/or possibilities for dwelling in places that are familiar and comfortable (Galvin and Todres, 2011).

PTs need to approach a sedentary patient's perspectives to be helpful (Setchell et al, 2017) and they must be aware of the risk of enacting weight stigma and adding to the 
patient's feeling of failure (Setchell et al, 2015; Setchell et al, 2016). We argue that promoting wellbeing is a way of offering new possibilities to feel at home in physical activity - with a sense of belonging and even more deeply provides a space for mutual complementarity.

\section{Methodological strengths and limitations}

The hermeneutical approach allowed for adding both depth and breadth to the understanding of how people with severe obesity experience physical activity (Todres and Galvin, 2005) by providing data on both individual experiences as well as findings that describes how homogenous groups of men and women talked about their experiences.

The pre-understanding of the study was informed by phenomenological perspectives on well-being, and the hermeneutic approach enabled an on-going testing of the first author's pre-understanding during the FGIs (Churchill, 2012) as well as continuously reflecting with co-authors on the interpretation to enhance the trustworthiness of the findings by avoiding a reproduction of first author's subjective knowledge (Fleming, Gaidys, and Robb, 2003). The use of theory was a methodological support for examining the existential experiences of being physically active with others (Lindberg et al, 2016).

The prolonged engagement with the same participants and the repeated FGIs allowed a trustful relationship to develop among participants and with first author. This added to the trustworthiness of the study as it generated thick and rich descriptions of their experiences of the phenomenon of interest with sensitivity and familiarity to the context (Holloway and Galvin, 2016). 
The trustful relationship with the participants held the risk of violating them by using "The Trojan Horse" to extract descriptions of their lifeworld (Fog, 1992), however, by being sensitive to their non-verbal communication the first author was influenced by the emotions that existed within the groups (Churchill, 2012) and used it to guide the questions posed in a sensitive and respectful way.

The construction of homogenous gender focus groups were based on the preunderstanding, that that the meaning of weight, identity and language are genderspecific (Temple Newhook, Gregory, and Twells, 2015) and would impact the individual's experiences and expressions (Côté and Coutu, 2010). Moreover, it may be important to understand the wellbeing of a person in her/his gendered roles in everyday life (Young, 2002) and use the insights into gender differences for increasing wellbeing during intervention (Short, Yang and Jenkins, 2013).

The first authors pre-understanding of gender may be a limitation in this study, however gender is not perceived as binary being a female researcher may have prevented the discussion of sexual topics in the group of men (Barbour, 2008), whereas it may have contributed to the intense discussion of sexual issues in the group of women. However, the gendered groups allowed for reporting findings for women and men separately. It may be a limitation that the findings may not provide a solid understanding of feminine and masculine experiences of physical activity, however, it was not our intention to categorise the findings in this way but rather to notice how the groups talked about their experiences and this may provide insight suitable for future research, or may inform secondary analysis of studies or systematic reviews. Further research also needs to be more focused on LGBTI (Lesbian, Gay, Bisexual, Transgender, Intersex) issues within 
physical activity and obesity. It did not emerge as an issue in the present study, however it may be important to inform future lifestyle interventions programmes.

The methodological approach taken was found suitable to access insights from a population positioned as marginalized and vulnerable to stigma in society in an ethical manner (Jones, Brown, and Holloway, 2013)

\section{$\underline{\text { CONCLUSION }}$}

The study contributes experiences of how individuals with severe obesity address, talk and refer to their experiences of being active with others during lifestyle intervention and points to some subtleties between men and women in this present study. It provides insight into the importance of wellbeing as a sense of feeling at home in physical activity, and how the achievement of wellbeing in physical activity can be challenged by intersubjective and spatial dimensions of absences of wellbeing such as feeling unsafe among other people and being vulnerable to failure, and even experiencing aversion and shame. Individuals with severe obesity want to be active, they strive for wellbeing in physcial activity and they struggle to tackle the existential challenges it holds. The findings can guide PTs to a deeply person-oriented practice when designing, conducting or developing individual or group-based physical activity interventions. Further research is suggested to focus upon the intersubjective experiences of wellbeing within different types of physical activity and settings in everyday life.

\section{Clinical implication}

This study provides empirical evidence of the lifeworld experiences of women and men living with severe obesity in relation physical activity. Insight into these existential experiences has implications for physiotherapy practice within physical activity 
promotion and lifestyle intervention. Our findings point to the importance of developing in-depth understanding of the individuals' perspectives of wellbeing, lack of wellbeing and suffering in relation to physical activity with others in order to prevent weight stigma during intervention. PTs may need to challenge the feminine/masculine lifestyles of the patients as well as recognize their own pre-understanding and gendered stereotypes. Moreover, PTs should be aware of the individuals' vulnerability regarding feelings of failure, aversion and shame as well as their possibilities of feeling at home in physical activity with others. PTs ability to recognize and address the existential aspects of physical activity may be valuable to increase health and wellbeing among individuals with severe obesity undergoing lifestyle intervention.

\section{DISCLOSURE OF INTEREST}

The authors report no conflict of interest.

\section{REFERENCES}

Aadland E, Robertson L 2012 Physical activityis associated with weight loss and increased cardiorespiratory fitness in severely obese men and women undergoing lifestyle treatment. Journal of Obesity.

Baillot A et al. 2015 Effects of lifestyle interventions that include a physical activitycomponent in class II and III obese individuals: a systematic review and metaanalysis. PLoS ONE 10: e0119017.

Barbour R 2008 Doing focus groups. Sage, London.

Baruth M, Sharpe PA, Parra-Medina D, Wilcox S 2014 Perceived barriers to exercise and healthy eating among women from disadvantaged neighborhoods: Results from a focus groups assessment. Women \& Health 54: 336-353.

Bombak AE 2015 Obese persons' physical activity experiences and motivations across weight changes: a qualitative exploratory study. BMC Public Health 15: 1129. 
Brach JS, Simonsick EM, Kritchevsky S, Yaffe K, Newman AB 2004 The association between physical function and lifestyle activity and exercise in the health, aging and body composition study. Journal of the American Geriatrics Society 52(4): 502-509.

Brinkmann S, Kvale S 2015 Interviews: Learning the craft of qualitative research interviewing (Vol. 3). Thousand Oaks, CA: Sage.

Bullington J 2006 Body and self: a phenomenological study on the ageing body and identity. Medical Humanities 32: 25-31.

Caspersen CJ, Powell KE, Christenson GM 1985 Physical activity, exercise, and physical fitness: definitions and distinctions for health-related research. Public Health Reports 100: 126-131.

Christiansen B, Borge L, Fagermoen MS 2012 Understanding everyday life of morbidly obese adults-habits and body image. International Journal of Qualitative Studies on Health and Well-being 7:17255.

Churchill S 2012 Resoundings of the flesh: Caring for others by way of "second person" perspectivity. International Journal of Qualitative Studies on Health and Wellbeing 7: 8187 .

Colucci E 2007 Focus groups can be fun: the use of activity-oriented questions in focus group discussions. Qualitative Health Research 17:1422-1433.

Côté D, Coutu M 2010 A critical review of gender issues in understanding prolonged disability related to musculoskeletal pain: how are they relevant to rehabilitation?

Disability and Rehabilitation 32: 87-102.

Dahl U, Rise MB, Kulseng B, Steinsbekk A 2014 Personnel and Participant Experiences of a Residential Weight-Loss Program. A Qualitative Study. PloS One 9: e100226.

Danielsen KK, Sundgot-Borgen J, Rugseth G 2016 Severe Obesity and the Ambivalence of Attending Physical Activity: Exploring Lived Experiences. Qualitative Health Research 26:685-696.

Danish National Board of Health 2010 Mænds sundhed - en oversigt overmænds sundhedstilstand og en gennemgang af effektive forebyggelsesmetoder [Men's health: An overview of men's health and review of effective prevention methods]. Danish National Board of Health, Copenhagen, Denmark. https://www.sst.dk//media/Udgivelser/2010/Pub12010/CFF/MaendsSundhed/M\%C3\%A6nds-sundhed,-d-,Oversigt-over-m\%C3\%A6nds-sundhedstilstand-og-gennemgang-af-effektiveforebyggelsesmetode.ashx

Denison FC, Weir Z, Carver H, Norman JE, Reynolds RM 2015 Physical activity in pregnant women with Class III obesity: A qualitative exploration of attitudes and behaviours. Midwifery 31: 1163-1167. 
Dikareva A, Harvey W, Cicchillitti M, Bartlett S, Andersen R 2016 Exploring perceptions of barriers, facilitators, and motivators to physical activity among female bariatric patients: implications for physical activity programming. American Journal of Health Promotion 30: 536-544.

Donnelly JE, Blair SN, Jakicic JM, Manore MM, Rankin JW, Smith BK 2009 American College of Sports Medicine Position Stand. Appropriate physical activity intervention strategies for weight loss and prevention of weight regain for adults. Medicine and Science in Sports and Exercise 41: 459-471.

Ekkekakis P, Lind E 2006 Exercise does not feel the same when you are overweight: the impact of self-selected and imposed intensity on affect and exertion. International Journal of Obesity 30: 652-660.

Fleming V, Gaidys U, Robb Y 2003 Hermeneutic research in nursing: developing a Gadamerian-based research method. Nursing Inquiry 10: 113-120.

Fog J 1992 Den moralske grund i det kvalitative forskningsinterview [The moral ground in the qualitative research interview]. Nordisk Psykologi 44: 212-229.

Folkesundhed, Den Nationale Rapport for 2006 Giv borgerne et kram [Give the citizens a hug]." Retrieved 09/06, 2020, from https://sum.dk/ /media/Filer\%20\%20Publikationer i pdf/2006/giv borgerne et kram.pdf)

Gadamer, HG, Specht EK, Stegmüller W, Connolly JM, Keutner T 1988 Hermeneutics versus science? Three German views. University of Notre Dame Press, Notre Dame.

Gadamer HG, Misgeld D, Nicholson G 1992 Hans-Georg Gadamer on education, poetry, and history: applied hermeneutics. State University of New York Press, Albany.

Gadamer H 1975/2013 Truth and Method. Bloomsbury Publishing, London.

Galvin K, Todres L 2011 Kinds of well-being: A conceptual framework that provides direction for caring. International Journal of Qualitative Studies on Health and Wellbeing 6: 10.3402 .

Galvin K, Todres L 2013 Caring and well-being : a lifeworld approach. Routledge, Milton Park, Abingdon, Oxon; New York, NY.

Groven KS, Heggen K 2018 Physiotherapists' encounters with “obese” patients: Exploring how embodied approaches gain significance. Physiotherapy Theory and Practice 34: 346-358.

Groven KS, Engelsrud G 2010 Dilemmas in the process of weight reduction: Exploring how women experience training as a means of losing weight. International Journal of Qualitative Studies on Health and Well-being 5: 10.3402.

Haga BM, Furnes B, Dysvik E, Ueland V 2019a Aspects of well-being when struggling with obesity. International Journal of Qualitative Studies on Health and Well-being 14: 1699637. 
Haga BM, Furnes B, Dysvik E, Ueland V 2019b Putting life on hold: lived experiences of people with obesity. Scandinavian Journal of Caring Sciences, .

Han S, Agostini G, Brewis AA, Wutich A 2018 Avoiding exercise mediates the effects of internalized and experienced weight stigma on physical activity in the years following bariatric surgery. BMC Obesity 5: 18.

Heidegger M. 1962/2008 Being and Time. Harper \& Row, New York.

Hills AP, Byrne NM 2004 Physical activity in the management of obesity. Clinics in Dermatology 22: 315-318.

Hitch D, Pépin G, Stagnitti K 2014 In the footsteps of Wilcock, part one: the evolution of doing, being, becoming, and belonging. Occupational Therapy in Health Care 28: 231-246.

Holloway I, Galvin K 2016 Qualitative research in nursing and healthcare, John Wiley \& Sons.

Holroyd AEM 2007 Interpretive hermeneutic phenomenology: Clarifying understanding. Indo-Pacific Journal of Phenomenology 7.

Hunger JM, Major B, Blodorn A, Miller CT 2015 Weighed down by stigma: how weight-based social identity threat contributes to weight gain and poor health, Social and Personality Psychology Compass 9: 255-268.

Hunt K, Lewars H, Emslie C, Batty GD 2007 Decreased risk of death from coronary heart disease amongst men with higher 'femininity'scores: a general population cohort study. International Journal of Epidemiology 36: 612-620.

Jones I, Brown L, Holloway I 2013 Qualitative research in sport and physical activity. SAGE, London.

Krueger RA, Casey MA 2009 Focus groups: a practical guide for applied research. 4th edn, Sage Publications, Los Angeles.

Lewis S, Thomas SL, Hyde J, Castle DJ, Komesaroff PA 2011A qualitative investigation of obese men's experiences with their weight. American Journal of Health Behavior 35: 458-469.

Lindberg E, Österberg S, Hörberg U 2016 Methodological support for the further abstraction of and philosophical examination of empirical findings in the context of caring science. International Journal of Qualitative Studies on Health and Well-being 11: 30482 .

Mik-Meyer N 2014 Health promotion viewed in a critical perspective. Scandinavian Journal of Public Health 42: 31-35.

Monaghan LF, Malson H 2013 It's worse for women and girls': Negotiating embodied masculinities through weight-related talk. Critical Public Health 23: 304-319. 
Morgan DL 1997 Focus groups as qualitative research. 2nd edn, Sage, Thousand Oaks, Calif.; London.

Natvik E, Råheim M, Andersen JR, Moltu C 2018 Living a successful weight loss after severe obesity. International Journal of Qualitative Studies on Health and Well-being 13: 1487762.

Nussbaum MC 2009 Hiding from humanity: Disgust, shame, and the law. Princeton University Press.

Piana N, Battistini D, Urbani L, Romani G, Fatone C, Pazzagli C, Laghezza L, Mazzeschi C, De Feo P 2013 Multidisciplinary lifestyle intervention in the obese: its impact on patients' perception of the disease, food and physical exercise. Nutrition, Metabolism, and Cardiovascular Diseases 23: 337-343.

Pickett AC, Cunningham GB 2017 Creating Inclusive Physical Activity Spaces: The Case of Body-Positive Yoga. Research Quarterly for Exercise and Sport 88: 329-338.

Pickett AC, Cunningham GB 2016 Physical Activity for Every Body: A Model for Managing Weight Stigma and Creating Body-Inclusive Spaces. Quest 69 : 19-36.

Psychiatric Center North Zealand and Psychiatric Research Unit 2017 The WHO-5. Capital Region, Copenhagen Denmark. https://www.psykiatri-regionh.dk/who5/Pages/default.aspx.

Puhl RM, Heuer CA 2010 Obesity stigma: important considerations for public health. American Journal of Public Health 100: 1019-1028.

Puhl RM, Heuer CA 2009 The stigma of obesity: a review and update. Obesity 17: 941-964.

Rand K, Vallis M, Aston M, Price S, Piccinini-Vallis H, Rehman L, Kirk SF 2017 It is not the diet; it is the mental part we need help with. A multilevel analysis of psychological, emotional, and social well-being in obesity. International Journal of Qualitative Studies on Health and Well-being 12: 1306421.

Saltonstall R 1993 Healthy bodies, social bodies: men's and women's concepts and practices of health in everyday life. Social Science \& Medicine 36: 7-14.

Setchell J, Gard M, Jones L, Watson B 2017 Addressing weight stigma in physiotherapy: Development of a theory-driven approach to (re) thinking weight-related interactions. Physiotherapy Theory and Practice 33: 597-610.

Setchell J, Watson B, Jones L, Gard M 2015 Weight stigma in physiotherapists: implications for education, practice and physiotherapy. Physiotherapy 101: e1369e1370.

Setchell J, Watson BM, Gard M, Jones L 2016 Physical Therapists' Ways of Talking About Overweight and Obesity: Clinical Implications. Physical Therapy 96: 865. 
Short SE, Yang YC, Jenkins, TM 2013 Sex, gender, genetics, and health. American Journal of Public Health 103: S93-S101.

Skea ZC, Aceves-Martins M, Robertson C, De Bruin M, Avenell A, REBALANCE Team 2019 Acceptability and feasibility of weight management programmes for adults with severe obesity: a qualitative systematic review. BMJ Open 9: e029473-2019029473.

Smythe EA, Ironside PM, Sims SL, Swenson MM, Spence DG 2008 Doing Heideggerian hermeneutic research: A discussion paper. International Journal of Nursing Studies 45: 1389-1397.

Tarrant M, Khan SS, Farrow CV, Shah P, Daly M, Kos K 2017 Patient experiences of a bariatric group programme for managing obesity: A qualitative interview study. British Journal of Health Psychology 22: 77-93.

Tate DF, Jeffery RW, Sherwood NE, Wing RR 2007 Long-term weight losses associated with prescription of higher physical activity goals. Are higher levels of physical activity protective against weight regain? The American Journal of Clinical Nutrition 85: 954-959.

Temple Newhook J, Gregory D, Twells L 2015 'Fat girls' and 'big guys': gendered meanings of weight loss surgery. Sociology of Health \& Illness 37: 653-667.

Thomas SL, Hyde J, Karunaratne A, Kausman R, Komesaroff PA 2008" They all work... when you stick to them": A qualitative investigation of dieting, weight loss, and physical exercise, in obese individuals. Nutrition Journal 7: 34.

Todres, L. and Galvin K (2005). "Pursuing both breadth and depth in qualitative research: illustrated by a study of the experience of intimate caring for a loved one with Alzheimer's disease. International Journal of Qualitative Methods 4: 20-31

Todres L, Galvin K 2010 "Dwelling-mobility": An existential theory of well-being. International Journal of Qualitative Studies on Health and Well-being 5: 10.3402.

Toft BS, Galvin K, Nielsen CV, Uhrenfeldt L 2020. Being active when living within a large body: experiences during lifestyle intervention. International Journal of Qualitative Studies on Health and Well-being 10: 1736769.

Toft BS Nielsen CV Uhrenfeldt L 2020 Balancing one's mood: experiences of physical activityin adults with severe obesity 18 months after lifestyle intervention. Zeitschrift für Evidenz, Fortbildung und Qualitaet im Gesundheitswesen : .

Toft BS, Uhrenfeldt L 2015 The lived experiences of being physically active when morbidly obese: A qualitative systematic review. International Journal of Qualitative Studies on Health and Well-being 10: 28577.

Ueland V 2019 Stigmatisation and shame-a qualitative study of living with obesity. Norwegian Journal of Clinical Nursing/Sykepleien Forskning, 14: e-77012. 
Ueland V, Dysvik E, Furnes B 2020 Living With Obesity: Expressions of Longing. SAGE Open Nursing 6: 2377960819901193.

Ueland V, Furnes B, Dysvik E, Rørtveit K 2019 Living with obesity-existential experiences. International Journal of Qualitative Studies on Health and Well-being 14: 1651171.

Vartanian LR, Novak SA 2011 Internalized societal attitudes moderate the impact of weight stigma on avoidance of exercise. Obesity 19: 757-762.

Wadden TA, Butryn ML, Byrne KJ 2004 Efficacy of Lifestyle Modification for LongTerm Weight Control. Obesity Research 12: 151-162.

White A, McKee M, Richardson N, Visser R, Madsen SA, Sousa B, Hogston R, Zatonski W, Makara P 2011 Europe's men need their own health strategy. BMJ (Clinical research ed) 343: d7397.

Wiklund M, Olsen MF, Willen C 2011 Physical activity as viewed by adults with severe obesity, awaiting gastric bypass surgery. Physiotherapy Research International : The Journal for Researchers and Clinicians in Physical Therapy 16: 179-186.

World Health Organization (WHO) 2014 Obesity and inequities. Guidance for addressing inequities in overweight and obesity.

http://www.euro.who.int/_ data/assets/pdf file/0003/247638/obesity-090514.pdf.

World Health Organization (WHO) 1986 Ottawa Charter for Health Promotion. http://www.bvsde.paho.org/bvsacd/cd68/paho557/annex.pdf.

World Medical Association 2013 Declaration of Helsinki: ethical principles for medical research involving human subjects. Jama 310: 2191-2194.

Young IM 2002 Lived body vs gender: Reflections on social structure and subjectivity. Ratio 15: 410-428. 
Table 2 In-door and out-doors physical activities offered during the in-hospital lifestyle intervention programme

Guided physical activity and exercise session at self-chosen type, duration and intensity (up to five sessions/day) Possibilities of extra leisure time activities

(Theoretical sessions on: inactivity/ physical activity in everyday life/exercise, goalsetting and planning)

\begin{tabular}{|l|l|l|}
\hline \multicolumn{1}{|c|}{ In-door gym } & Outdoor in park, forest or garden & \multicolumn{1}{c|}{ In-door hot pool } \\
\hline Circle training with own body weight & Social walks & Balance and collaboration exercises \\
\hline $\begin{array}{l}\text { Resistance training with simple } \\
\text { equipment }\end{array}$ & Bike/electric bike riding & Stretching and mobility exercises \\
\hline Dancing and playing & Cardio interval training & Cardio fitness and relay race \\
\hline Ball games and sports & Nordic walking & Relaxation exercises \\
\hline Yoga, meditation and mindfulness & Mindful walking & \\
\hline Gymnastics on chair & Functional training & \\
\hline Peristaltic pump exercises & Strength training & \\
\hline Balance exercises on a large ball & Full moon walk (occasionally) & \\
\hline Access to fitness equipment & Garden games & \\
\hline
\end{tabular}

